\title{
Synergistic nano-tribological interaction between zinc dialkyldithiophosphate (ZDDP) and methyl oleate for biodiesel-fueled engines
}

\author{
Siti Hartini HAMDAN ${ }^{1}$, Chiew Tin $\mathrm{LEE}^{2}$, Mei Bao $\mathrm{LEE}^{2}$, William Woei Fong CHONG ${ }^{2,3,}{ }^{*}$, Cheng Tung CHONG ${ }^{4}$, \\ Suhaila Mohd SANIP ${ }^{5}$ \\ ${ }^{1}$ Bio-Engineering Technology Department, University Kuala Lumpur Malaysian Institute of Chemical \& Bioengineering \\ Technology (UniKL MICET), Alor Gajah 78000, Malaysia \\ ${ }^{2}$ School of Mechanical Engineering, Faculty of Engineering, Universiti Teknologi Malaysia (UTM), Johor Bahru 81310, \\ Malaysia \\ ${ }^{3}$ Automotive Development Centre (ADC), Universiti Teknologi Malaysia (UTM), Johor Bahru 81310, Malaysia \\ ${ }^{4}$ China-UK Low Carbon College, Shanghai Jiao Tong University, Shanghai 201306, China \\ ${ }^{5}$ Faculty of Engineering and Physical Sciences, University of Southampton Malaysia (UoSM), Iskandar Puteri 79200, Malaysia \\ Received: 02 December 2019 / Revised: 19 March 2020 / Accepted: 07 July 2020
}

(C) The author(s) 2020.

\begin{abstract}
In biodiesel-fueled compression-ignition (CI) engines, dilution by unburned biodiesel has been found to have adverse effects on the boundary lubrication properties of additives in fully formulated engine lubricants. Such dilution of engine lubricants could be even more pronounced for CI engines running on higher blend concentrations of biodiesel. Given the nanoscopic nature of the interaction, this study seeks to determine the nano-tribological properties of an engine lubricant additive (e.g., zinc dialkyldithiophosphate (ZDDP)) when diluted with a fatty acid methyl ester (e.g., methyl oleate). Using lateral force microscopy (LFM) together with a fluid imaging technique, the lowest nanoscopic friction forces and coefficient of friction values (0.068-0.085) were measured for ZDDP when diluted with 70 vol\% of methyl oleate. These values are also observed to be lower than those measured for neat ZDDP and neat methyl oleate, respectively, under similar conditions. Subsequently, interpreting the data with the Eyring thermal activation energy approach, it could then be elucidated that the lower frictional losses observed for the contact lubricated with this volumetric mixture are a result of the lower potential energy barrier and activation energy required to initiate sliding. These energy values are approximated to be $2.6 \%$ and $28.9 \%$ (respectively) lower than that of the contact lubricated with neat ZDDP. It was also found that the mixture, at this volumetric concentration, possesses the highest possible pressure activation energy (load-carrying capacity) along with the lowest possible shear activation energy (shearing), potentially indicating optimum tribological conditions for boundary lubrication. Thus, the findings of this study suggest that an optimum concentration threshold exists in which a synergistic nano-tribological interaction between additives and fatty acid methyl esters can be attained, potentially reducing boundary frictional losses of lubricated conjunctions. Such findings could prove to be essential in effectively formulating synergistic additive concentrations for engine lubricants used in biodiesel-fueled CI engines.
\end{abstract}

Keywords: boundary lubrication; lateral force microscopy; thermal activation energy; methyl ester; boundary additives

\footnotetext{
* Corresponding author: William Woei Fong CHONG, E-mail: william@utm.my
} 


\section{Introduction}

The International Energy Agency (IEA) outlined that the transportation sector consumes up to $65.1 \%$ of the total consumption of oil and oil products globally [1]. In the transportation sector, an estimated total of 95.7 million vehicles were produced worldwide in 2018 [2]. Further breaking down the vehicles based on categories, approximately $26.8 \%$ of this total comprises heavy duty vehicles, such as commercial vehicles, trucks, buses, and coaches. Interestingly, the majority of these vehicles are manufactured to run on petrodiesel fuel, further corroborating the findings from the IEA, where $36 \%$ of the total consumption of oil and oil products is petrodiesel [1]. In the midst of decarbonizing the transportation sector by moving away from fossil fuel, biodiesel has emerged as an interesting alternative to petrodiesel. This alternative fuel, when blended with petrodiesel at reasonably small concentrations, has over the years been proven to be capable of significantly reducing emissions of carbon monoxide and unburned hydrocarbons as compared to petrodiesel [3-6].

To date, first-generation biodiesel is still the most commonly produced biodiesel worldwide [7]. Firstgeneration biodiesel is typically derived from food crops, mainly palm oil, soybean oil, rapeseed, and sunflower oil $[7,8]$. However, the increased production of biodiesel from such food crops has led to the shrinkage of land area originally meant for food crop cultivation, resulting in food-fuel competition [9]. In view of this undesirable impact, the research community has now shifted their focus to explore the feasibility of using non-food crop feedstocks $[10,11]$, biomass [12], and microorganisms [13, 14] to produce second- and third-generation biofuels. One of the most highly focused on feedstocks for deriving second-generation biodiesel is waste cooking oil, which is abundant and often disposed of [7].

Even though the adoption of biodiesel has been proven to be beneficial in terms of emissions, its long-term effects on the operating life span of compression-ignition (CI) engines are still being extensively researched, especially for engine in-cylinder lubrication systems. The tribological performance of biodiesel is often studied to determine its lubricity when blended with petrodiesel [15]. This is essential, considering the possibility of clogging when such a fuel blend is being injected through the fuel injector. Other notable studies include those from Geller and Goodrum [16] and Knothe and Steidley [17]. However, it is also known that the injected fuel in a CI engine does not completely burn within the combustion chamber. This non-negligible amount of unburned fuel could impinge on the engine cylinder liner, resulting in fuel dilution of the engine lubricant. Studies have found that such dilution phenomenon could be even more acute when CI engines are fueled with biodiesel [18, 19]. This is because biodiesel has a higher boiling point than petrodiesel [20].

When biodiesel of B20 (20\% biodiesel and $80 \%$ petrodiesel blend) was used in a CI engine with post-injection capability, Kotrba observed that a biodiesel accumulation of up to $40 \%$ could be found along the engine cylinder walls [21]. It was also highlighted in their study that a dilution level above $50 \%$ results in increased wear. If changes in the lubricant are not performed more regularly, this could possibly induce untimely engine failure. Other investigations by Fang et al. [22], Shanta et al. [23], and Gulzar et al. [24] also detected a much more severe wear behavior occurring along the contact conjunction when the engine lubricant was diluted by biodiesel. They observed that such undesirable tribological impact is due to the fatty acid methyl ester molecules, which reduce the effectiveness of additives such as zinc dialkyldithiophosphate (ZDDP), in forming a protective coating on the metal surfaces.

In contrast to the previously reported literature, Arumugam and Sriram found that wear and friction force actually reduce when biodiesel contaminates a commercial synthetic engine lubricant [25]. However, their tests only introduced up to $10 \mathrm{vol} \%$ of biodiesel to the engine lubricant. Using jathropha oil-derived biodiesel, Singh et al. [26] also measured wear improvement when $4 \mathrm{vol} \%$ and $12 \mathrm{vol} \%$ of such biodiesel were added to an engine lubricant. Singh and Goel [27] also observed improved wear and frictional behavior with a $10 \mathrm{vol} \%$ blending of waste cooking oil-derived biodiesel with engine lubricant. Thus far, contradicting tribological performances have been revealed for low levels of biodiesel dilution of engine lubricants. 
The possible adverse tribological performance of engine lubricants with biodiesel dilution could be resolved by changing the lubricant more regularly. However, it remains a challenge to provide continuous real-time monitoring of the engine lubricant condition [28], especially for biodiesel-operated engines, in order to accurately determine the required regularity of the engine lubricant change. Therefore, in order to better understand the tribological impact of biodiesel dilution of engine lubricants, it is crucial to fundamentally identify the operating lubrication regime that is adversely affected. For engine incylinder lubrication, the operating lubrication regimes range from hydrodynamic to boundary lubrication regimes [29]. The hydrodynamic lubrication regime involves the shearing of a sufficiently thick lubricant film, often Newtonian in behavior. Theoretically, the shearing of lubricant film along this regime is dominated by bulk rheological properties, such as viscosity. In this case, the dilution of the engine lubricant is expected to lower the viscosity of the lubricant, potentially resulting in lower hydrodynamic frictional losses. This is supported by the need to operate machine elements using lubricants of lower viscosity [30].

Along mixed and boundary lubrication regimes, the effectiveness of the lubrication film is influenced by the formation of a boundary film due to additives. The boundary film acts as the last barrier in preventing direct surface asperity interactions. From the literature, it has been highlighted that the biodiesel dilution of engine lubricants could affect the tribological performance of boundary additives, potentially leading to increased material wear. Typically, measuring frictional properties along these operating lubrication regimes involves the use of a four-ball tester [31-33], high frequency reciprocating rig (HFRR) [27], or even tribometers configured for ball-on-flat [34, 35] and pin-on-disk [26, 27, 36].

However, the characterized boundary lubrication properties at the micro- to macro-scale, using the tribometers mentioned above, could still be a result of the coupling between the shearing of boundary films and direct metal-to-metal interactions at the asperity level (dry friction). Figure 1 illustrates opposing rough surfaces in relative motion, while

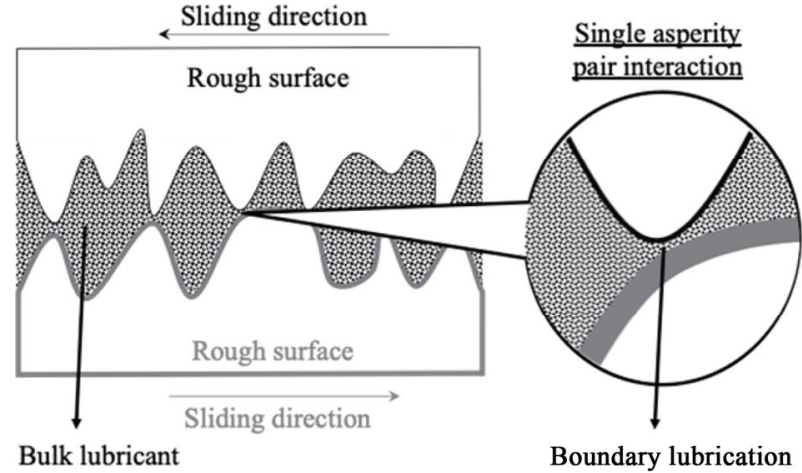

Fig. 1 Surface asperity interaction separated by adsorbed molecularly thin film formation.

being separated by a lubricant film. To characterize the boundary film, having the capacity to measure the tribological properties at the asperity pair level could prove to be essential. An alternative approach for isolating the shearing of boundary films formed at surface asperity was reported by Maru et al., using an atomic force microscope to measure the nanoscale frictional behavior of a standard reference biodiesel [37]. A similar approach, using lateral force microscopy (LFM) coupled with a fluid imaging technique, has also recently been adopted by Chong and $\mathrm{Ng}$ to measure the nano-tribological properties of various types of biodiesel [38].

To date, most studies on biodiesel diluting of engine lubricants reported in the literature mainly involve tribological characterization approaches at the micro-to-macro length scale. This lacks the capacity to fundamentally elucidate the underlying mechanisms affecting the formation of boundary films by engine lubricants when diluted with biodiesel, which is nanoscopic in nature. Therefore, the present study aims to determine the tribological properties of engine lubricants in the presence of biodiesel at the surface asperity level using LFM together with a fluid imaging technique. The present study extends the work of Hamdan et al. [39], where the impact of palm oil-derived biodiesel diluting various types of fully formulated SAE grade engine lubricants was investigated using a pin-on-disk tribometer. In their study, they found that an acceptable tribological threshold of biodiesel dilution exists for different types of engine lubricants, in which any dilution levels beyond this threshold are observed to increase 
the boundary friction force. Complementing the previous study with such a nanoscopic investigation will benefit the fundamental elucidation of the interaction of biodiesel with engine lubricants, especially additives, at the molecular level. Such fundamental knowledge could prove to be significant in theoretically aiding the additive package selection for lubricants designed for use in biodiesel-fueled engines, rather than resorting to the trial-and-error approach commonly adopted in the lubricant industry.

\section{Experimental approach}

For characterization at such diminished-length scales, boundary lubrication is expected to be localized (highlighted in Fig. 1), where molecular interactions between lubricant additives and biodiesel molecules prevail. It has been elucidated in the literature above that the introduction of biodiesel to engine lubricants reduces the effectiveness of additives, such as ZDDP, in forming effective protective films on metal surfaces in relative motion. To narrow down the scope of the study, instead of using a fully formulated Society of Automotive Engineers (SAE) engine lubricant, the present study uses ZDDP as the base lubricant. With regard to biodiesel, the palm oil-derived biodiesel used by Hamdan et al. [39] is composed of methyl oleate (39\%) and methyl palmitate $(43.9 \%)$ as the two dominant molecular species. Comparing these two methyl ester species, the friction and wear measured for methyl oleate tend to be higher than those of methyl palmitate [17]. Considering the worst tribological case scenario, methyl oleate was selected as the representative biodiesel component in diluting ZDDP as the base oil.

Based on the initial approximations mentioned above, the present study focuses on determining the tribological properties of ZDDP as the base oil in the presence of methyl oleate molecules at various volumetric proportions. Commercially available ZDDP additives were obtained while methyl oleate was derived through the esterification process for the current analysis. Mixtures of methyl oleate-ZDDP at various volumetric proportions were prepared and tested using LFM coupled with a fluid imaging technique. This was followed by a thermal activation energy analysis of the different methyl oleate-ZDDP mixtures in order to comprehend the underlying factors influencing the measured tribological properties.

\subsection{Esterification of methyl oleate}

Esterification of a Food Chemicals Codex (FCC) compliant oleic acid, which was obtained from Sigma Aldrich (Product No. W281506), was carried out using a three-necked flask. A reflux condenser was attached to the center neck with a stopper and a thermometer inserted on the left and right neck, respectively. A mixture containing a 22:1 molar ratio of methanol to oleic acid, together with 0.05 mol ionic liquid (IL) catalyst, was loaded into the flask and vigorously stirred at a constant stirring rate. During this stirring process, the flask was submerged in an oil bath to heat the mixture to $70{ }^{\circ} \mathrm{C}$. Once the stirring process was completed (after $4 \mathrm{~h}$ ), the flask was removed from the oil bath before being placed in a water bath. This allowed the reaction mixture to cool down to room temperature. Subsequently, the reaction mixture was transferred to a separating funnel to allow for the separation of the product. After sitting at room temperature for $24 \mathrm{~h}$, the mixture was decanted while the remaining methanol, water, and impurities were removed using rotary evaporation under vacuum at $70{ }^{\circ} \mathrm{C}$. The final product was finally tested to ensure that a yield of at least $96.5 \%(\mathrm{~m} / \mathrm{m})$ and a maximum acid number of $0.5 \mathrm{mg} \mathrm{KOH} / \mathrm{g}$ of methyl oleate were obtained.

\subsection{Frictional conjunction}

In the current analysis, an atomic force microscope (AFM) with the capability of LFM and fluid imaging was used to measure the nanoscale frictional properties. A schematic diagram of the LFM coupled with the fluid imaging measurement setup, using an open liquid cell, is shown in Fig. 2. A silicon AFM probe with a tip curvature radius of approximately $10 \mathrm{~nm}$, sliding on a stainless steel substrate, was selected to represent a surface asperity pair contact. The friction tests were carried out for applied normal loads between 1 and $10 \mathrm{nN}$ at sliding velocities ranging from 2 to $200 \mu \mathrm{m} / \mathrm{s}$. For the selected applied normal loads, the resulting maximum Hertzian contact pressures were calculated to be in the range 


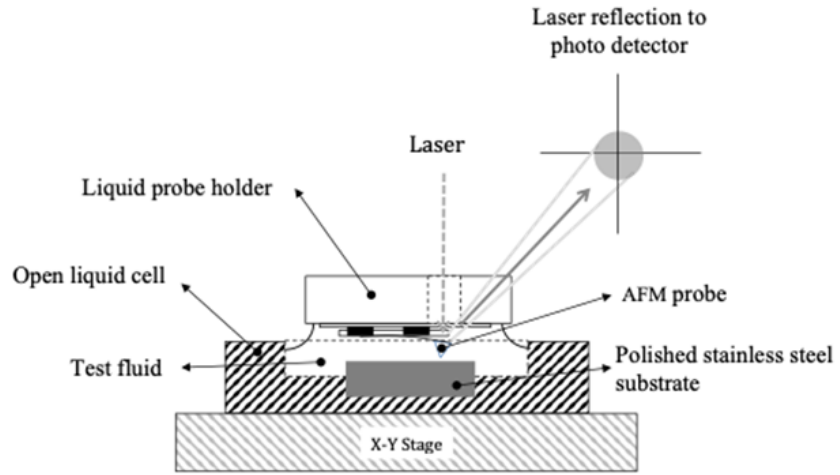

Fig. 2 Schematic diagram for LFM coupled with fluid imaging setup.

of 2.65 to $5.7 \mathrm{GPa}$. This was determined by taking the elastic modulus, $E_{\text {silicon }}=160 \mathrm{GPa}$, and Poisson's ratio, $v_{\text {silicon }}=0.27$, for the silicon AFM probe and elastic modulus, $E_{\text {steel }}=210 \mathrm{GPa}$, and Poisson's ratio, $v_{\text {steel }}=0.27$, for the stainless steel substrate.

The AFM probe and stainless steel substrate remained submerged in the tested lubricant throughout the test. For this study, the measurement approach followed the method adopted by Chong and Rahnejat [40], which has also been applied in other studies $[29,38]$. Figure 3 illustrates the surface topography of the stainless steel substrate that the AFM probe slides against, together with its corresponding lateral force trace-retrace signal at a sliding velocity of $20 \mu \mathrm{m} / \mathrm{s}$ and applied normal load of $10 \mathrm{nN}$. In order to minimize the surface roughness effect, the stainless steel substrate was mirror polished. Using non-contact mode AFM, for a scan area of $5 \mu \mathrm{m} \times$ $5 \mu \mathrm{m}$, the mean surface roughness, $\mathrm{Ra}$, and root mean square roughness, $\mathrm{Rq}$, for the tested polished

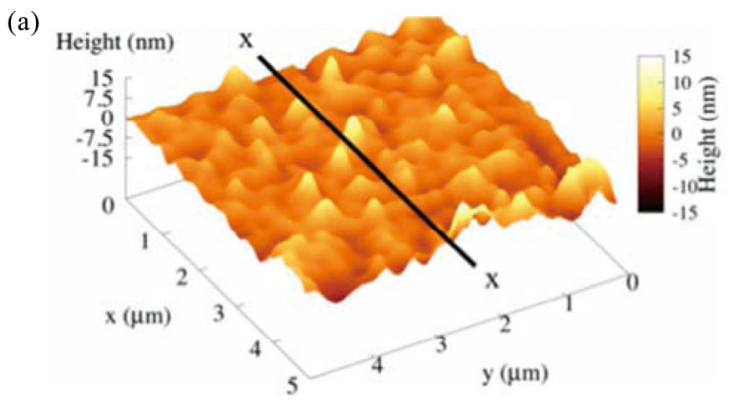

(a) stainless steel substrates were measured to be an average of 1.19 and $1.54 \mathrm{~nm}$, respectively. It should be noted that a new set of contact tips and stainless steel substrates were used for each of the tested fluid mixtures and their corresponding repeats.

\section{Analytical approach}

At lower sliding velocities, such as those prescribed for the friction test in this study, the nanoscale sliding contact is expected to be in the thermally activated region, resulting in thermally assisted atomic hopping to occur [41]. Therefore, to interpret the friction force measured using LFM for the tested mixtures, the Eyring thermal activation energy assumption was applied. The approach assumes that the motion of a molecule is regulated by a potential energy barrier, $E$, due to its neighboring molecules. To overcome this barrier and initiate sliding motion, the molecule must overcome the applied shear stress and pressure. This concept is illustrated in Fig. 4 with the height of the potential energy barrier, $E$, which is determined as follows:

$$
E=Q+P \Omega-\tau \phi
$$

where the terms $\Omega$ and $\phi$ are defined as the pressure activation volume and the shear acceleration volume, respectively. The pressure activation volume refers to the local increase in volume in order to allow for molecular motion to occur while the shear activation volume refers to the dislocation volume of the liquid along the tangential direction per unit shearing process [42]. The term $Q$ is known

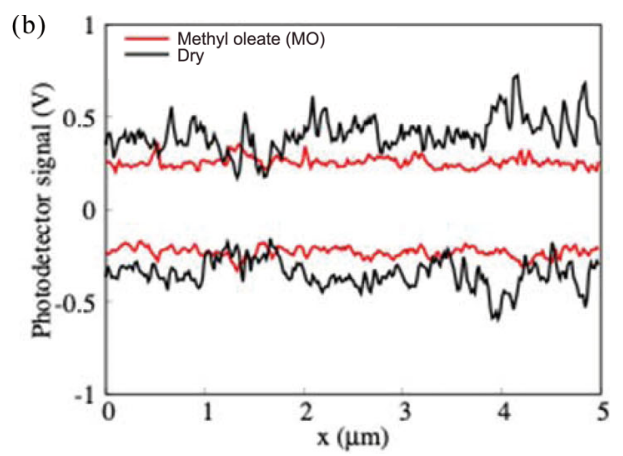

(b)

Fig. 3 Example data for LFM measurements at sliding velocity of $20 \mu \mathrm{m} / \mathrm{s}$ and applied normal load of $10 \mathrm{nN}$. (a) Measured surface topography. (b) Lateral force signal along $X-X$ direction along the scanned area. 


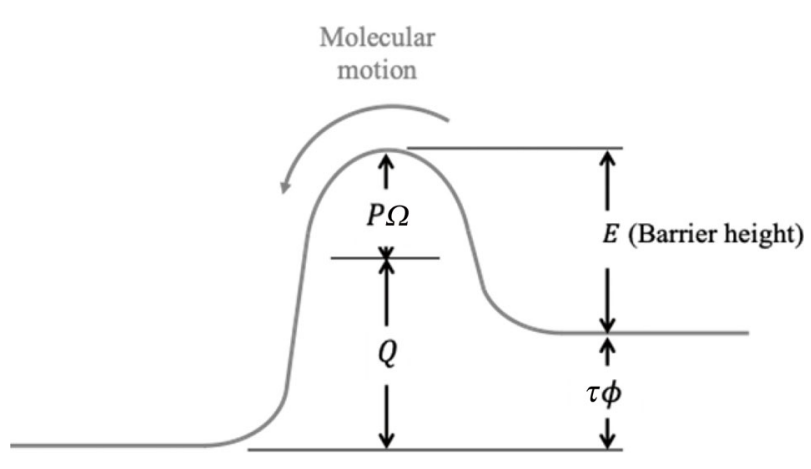

Fig. 4 Eyring thermal activation energy assumption.

as the activation energy to initiate sliding, while the terms $\tau$ and $P$ refer to the shear stress and the applied normal pressure, respectively.

In this model, to ascertain the thermal activation parameters, the average time for the molecule to overcome a potential energy barrier, $E$, is assumed to conform to a Boltzmann distribution. By correlating with the effective vibration frequency of the molecule, the shear stress of the contact during sliding can be expressed as follows [42]:

$$
\tau=\frac{k T}{\phi} \sinh ^{-1}\left(\frac{V}{2 V_{\mathrm{o}}} \mathrm{e}^{\frac{Q+P \Omega}{k T}}\right)
$$

where $V_{\mathrm{o}}$ is taken to be $20 \mathrm{~m} / \mathrm{s}$ [42]. It should be noted that Eq. (2) can be simplified by assuming that $\tau \phi / k T$ is larger than unity. However, it has been highlighted that such an assumption might not concur with the shear strength of the film, when operated over a larger range of temperatures [42]. Hence, in order to determine the thermal activation parameters, the measured frictional properties were instead curve-fitted with the more general Eq. (2), rather than the simplified approximations also given in Ref. [42]. The values for these parameters are necessary to identify the nature of the molecular mechanism under shear. The curve-fitting process was executed via a generalized reduced-gradient nonlinear fitting approach, where the Hertzian contact area and the contact pressure for sliding contact were assumed for this analysis. Aside from Langmuir-Blodgett films studied by Briscoe and Evans [42], it should be noted that interpretation of LFM-measured nano-frictional properties of fluids using this thermal activation energy assumption has also been reported in literature for methyl esters
[38], simple fluids (e.g., octamethylcyclotetrasiloxane and n-hexadecane) [43], and also ZDDP [44].

\section{Results and discussion}

To evaluate the studied lubricant mixture, the dynamic viscosities, $\eta$, for ZDDP and methyl oleate were first measured at temperatures between 25 and $100{ }^{\circ} \mathrm{C}$ using a Bohlin Gemini HR Nano rotational rheometer, as shown in Fig. 5. The dynamic viscosity of ZDDP was significantly higher than that of methyl oleate. Higher viscosity values, such as for ZDDP, typically result in the formation of a thicker lubricant film, which leads to a better load-carrying capacity of the film itself. On the contrary, under hydrodynamic action, these are instead expected to generate a higher friction force (Coutte viscous shear, $\tau \propto \eta$ ). As a result of such a tradeoff between the loadcarrying capacity and lubricant film shear, an effective lubricant film formation should supposedly possess optimum load-carrying capacity with the lowest possible shear stress. It should be noted that the dynamic viscosity measurements were repeated twice for each tested liquid with a maximum relative standard deviation of approximately $3.7 \%$. Hence, for clarity purposes, error bars were not included in presenting the dynamic viscosity data.

However, along the boundary lubrication operating regime, where surface asperity interactions prevail, shearing of the lubricant film no longer behaves in a Newtonian manner and is expected to be dominated by interfacial surface forces (e.g., solvation and van

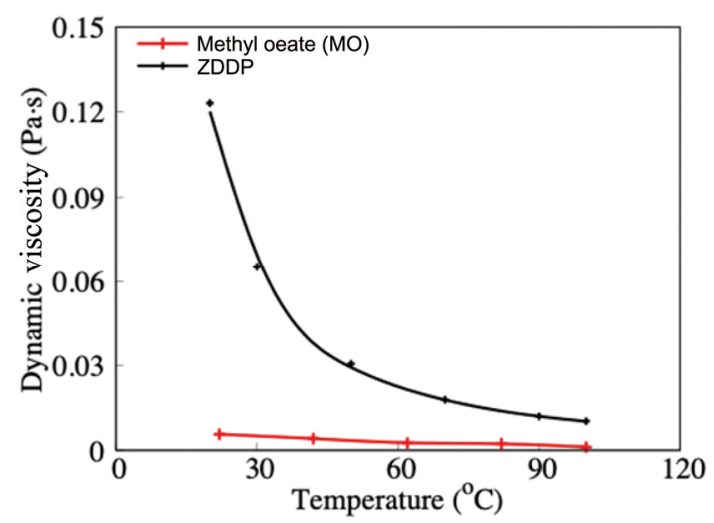

Fig. 5 Dynamic viscosity of ZDDP and methyl oleate measured at different temperatures. 
der Waals forces). Hence, it is imperative that characterization of boundary lubricant films be done at the surface asperity level. Figure 6 illustrates the force-displacement curve measured by indenting the AFM probe against the stainless steel substrate, when separated by the various methyl oleateZDDP mixtures. No negative adhesive forces were measured because the AFM probe and the stainless steel substrate were fully submerged in the tested liquid. As the Z-scanner displacement decreased, the reaction forces generated by the tested lubricants, experienced by the AFM probe, led to an increase in the measured normal forces. This could be correlated to the compressibility of the lubricant film. At most concentrations of methyl oleate added to ZDDP, the force increment with Z-scanner displacement was fairly similar. However, when 10 vol\% methyl oleate was blended with the ZDDP, a slower force increase with Z-scanner displacement was measured. This indicates a higher compressibility capacity of the tested methyl oleate-ZDDP mixture. Such increase in compressibility behavior could result in the formation of a thinner lubricant film along the sliding contact [45].

To further examine the boundary lubrication properties of various methyl oleate-ZDDP mixtures, Fig. 7 plots the measured friction force against varying applied normal loads at different AFM probe sliding velocities. These lateral-force measurements were repeated twice for each tested liquid mixture with a determined maximum relative standard deviation of approximately $5.9 \%$. In view of the relatively small deviation, error bars were not included in

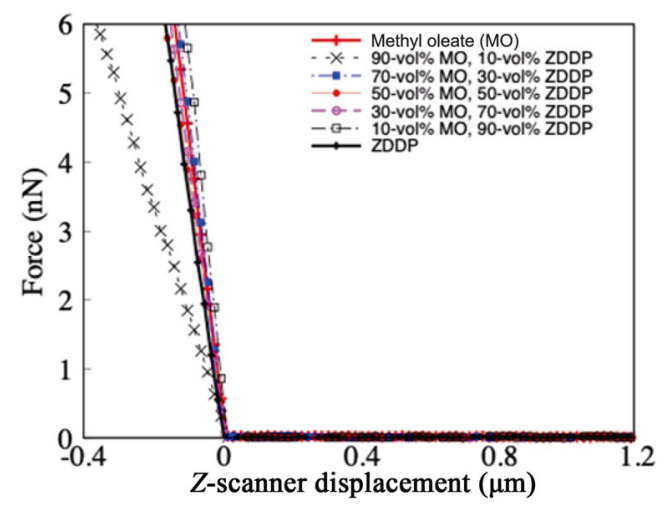

Fig. 6 Force-displacement curves for ZDDP with increasing amount of methyl oleate. presenting the friction force data for clarity purposes. The friction forces were determined to increase in a fairly linear manner with applied normal loads. The highest friction force was observed to be generated by the contact lubricated with ZDDP at most sliding velocities, except at $2 \mu \mathrm{m} / \mathrm{s}$. On the other hand, at all selected sliding velocities, the friction force was measured to be lowest for the lubricant mixture comprising $70 \mathrm{vol} \%$ methyl oleate and $30 \mathrm{vol} \%$ ZDDP. Interestingly, these friction force values are also notably lower than those generated by the contact lubricated with neat ZDDP and neat methyl oleate. This points to an optimum range of mixtures between methyl oleate and ZDDP molecules, where tribological synergy could be obtained at such a diminished-length scale. This observation also corroborates those reported in Refs. [26, 27], where there exists an optimum addition of fatty acid methyl ester (biodiesel) to typical engine lubricants that could lead to improved tribological performances.

Using the measured friction force as a function of the applied normal load, the coefficient of friction values for ZDDP with increasing amount of methyl oleate molecules were then mapped against the changing AFM probe sliding velocities, as shown in Fig. 8. Through the coefficient of friction map, it is shown that the lowest values, which are around 0.068 to 0.085 , could be achieved when methyl oleate was added to ZDDP at $70 \mathrm{vol} \%$. This is in line with the lower friction forces measured in Fig. 7. With methyl oleate compositions below $50 \mathrm{vol} \%$, the coefficient of friction values were observed to fluctuate with varying sliding velocities, illustrating the non-synergistic competitive interaction between ZDDP and methyl oleate molecules in inhibiting lubricity. Such a frictional trend could also lead to an adverse tribological trend.

The measured frictional properties shown above could still be insufficient in order to better-understand the underlying mechanisms for the observed nanotribological behavior of methyl oleate-ZDDP mixtures. Therefore, a thermal activation approach was adopted. Figure 9 shows the activation volume parameters based on Eyring thermal activation energy assumptions for ZDDP with increasing amounts of methyl oleate 

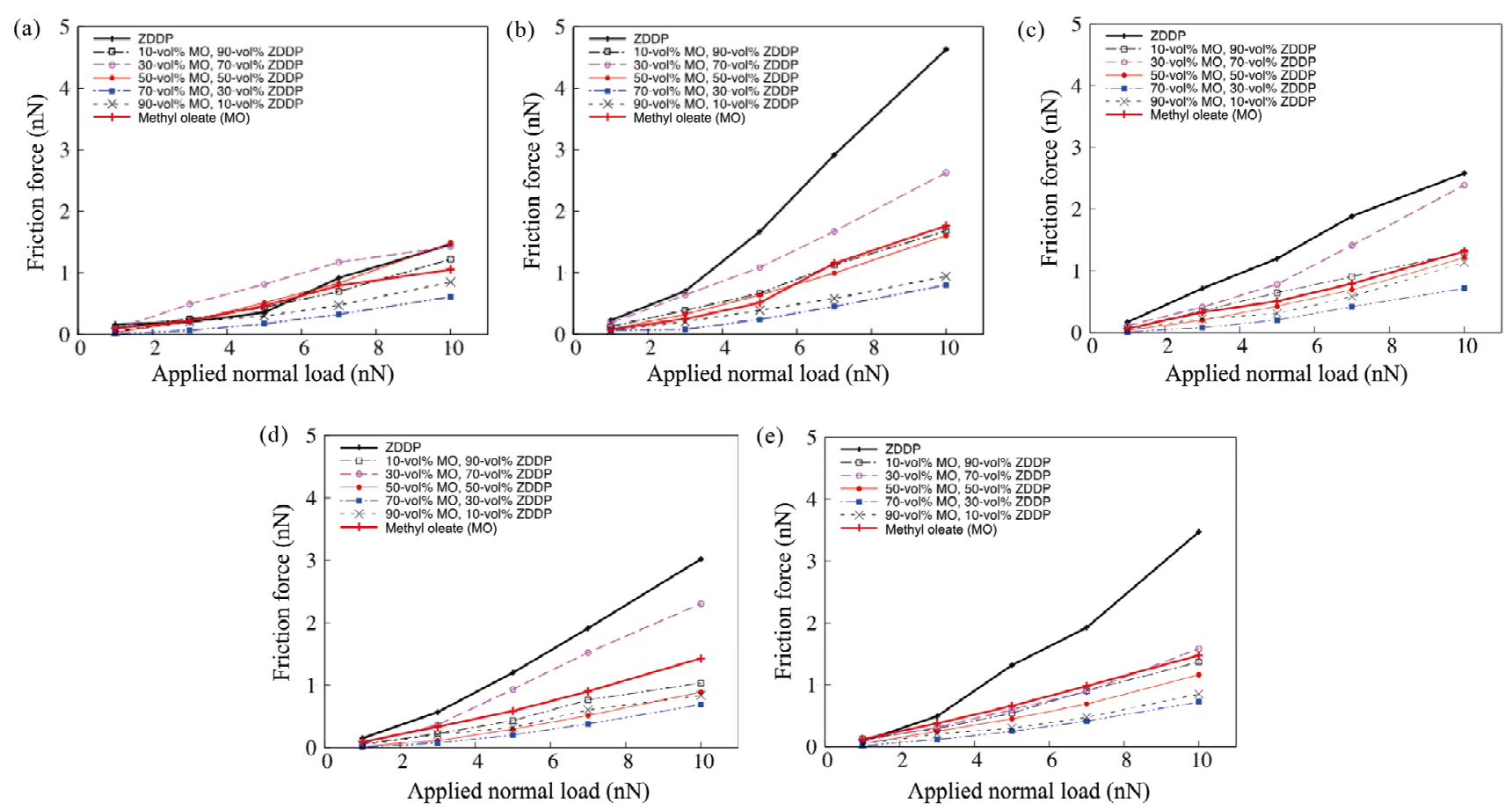

Fig. 7 Friction force measured for ZDDP with increasing amount of methyl oleate at different applied normal loads and AFM-probe sliding velocities: (a) $2 \mu \mathrm{m} / \mathrm{s}$, (b) $10 \mu \mathrm{m} / \mathrm{s}$, (c) $20 \mu \mathrm{m} / \mathrm{s}$, (d) $100 \mu \mathrm{m} / \mathrm{s}$, and (e) $200 \mu \mathrm{m} / \mathrm{s}$.

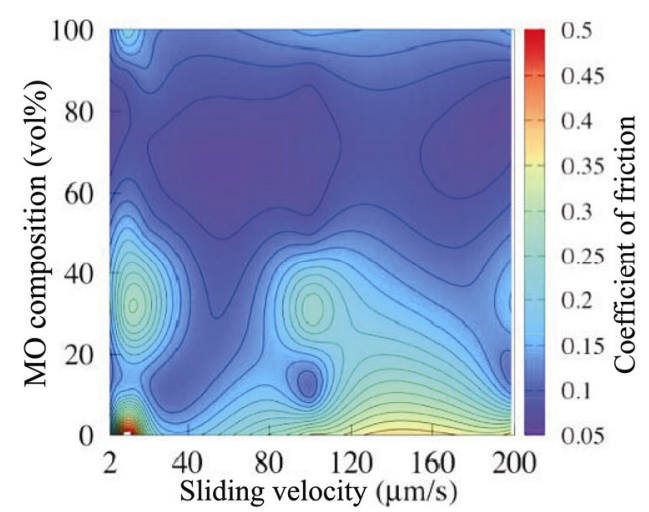

Fig. 8 Coefficient of friction for ZDDP with increasing amount of methyl oleate at varying AFM-probe sliding velocities.

molecules, at varying AFM-probe sliding velocities. It should be noted that curve-fitting of Eq. (2) to all the measured friction forces, via a generalized reducedgradient non-linear fitting approach, produced Rsquared values of at least 0.8765 . The shear stress activation volume, $\phi$, was observed to be approximately an order of magnitude larger than that of the pressure activation volume, $\Omega$. This is similar to the findings reported by Briscoe and Evans [42]. In Fig. 9(a), higher pressure activation volumes were calculated to be at a sliding velocity of approximately $40 \mu \mathrm{m} / \mathrm{s}$ at all levels of the methyl oleate-ZDDP mixtures. This reflects on a more significant increase in localized volume, giving rise to increased loadcarrying capacity under such operating conditions. For the shear stress activation volume, $\phi$, the higher activation volume region closely followed the ones observed for the pressure activation volume, but with a higher tendency to occur for methyl oleate compositions between 60 and $80 \mathrm{vol} \%$ across the range of tested sliding velocities. This shear activation volume trend indicates that more liquid molecules were being displaced during the shearing process.

With the activation volume parameters calculated above, the pressure activation energy $(P \Omega)$ and shear activation energy $(\tau \phi)$ could then be determined as illustrated in Figs. 10 and 11. It is shown that in most tested conditions, both of these activation energies increased with the applied normal load. However, the trend of these energies varied significantly with different methyl oleate-ZDDP mixtures at different sliding velocities. Comparatively, one of the notable observations indicated that the highest 

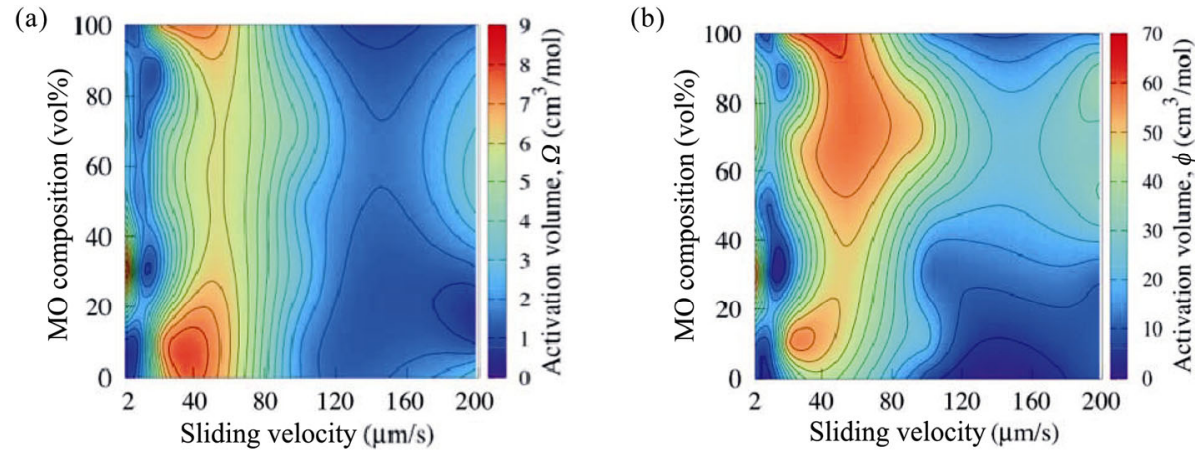

Fig. 9 Activation volume parameters for ZDDP with increasing amount of methyl oleate at varying AFM-probe sliding velocities: (a) pressure activation volume, $\Omega$; (b) shear stress activation volume, $\phi$.

(a)

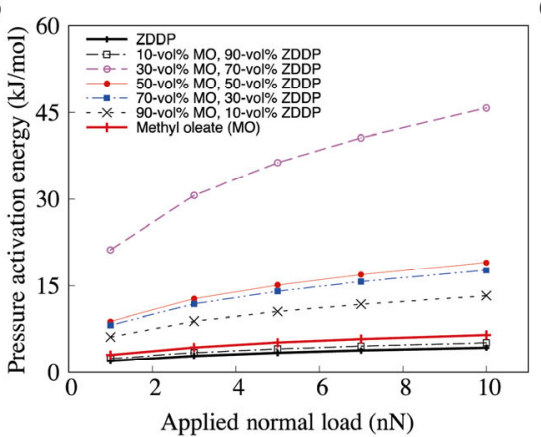

(b)

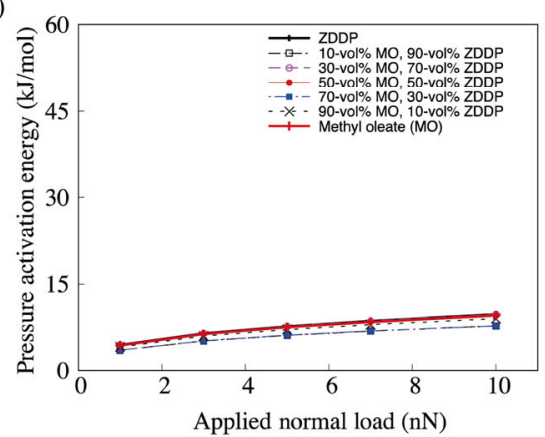

(c)

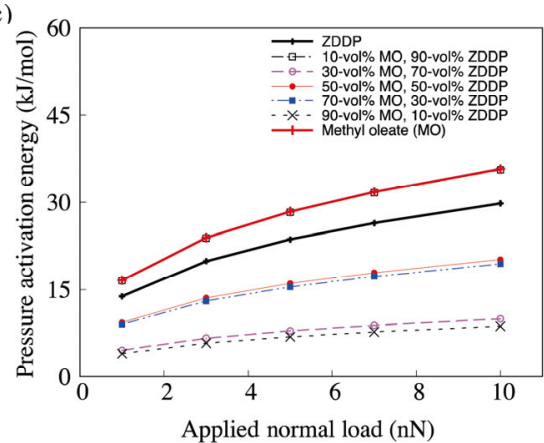

(d)
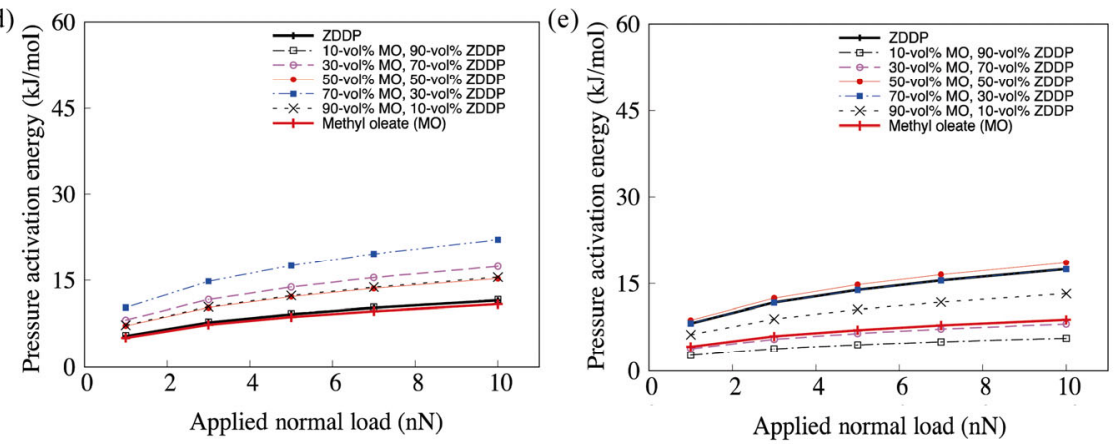

Fig. 10 Pressure activation energy values for ZDDP with increasing amount of methyl oleate at different applied normal loads and AFM-probe sliding velocities: (a) $2 \mu \mathrm{m} / \mathrm{s}$, (b) $10 \mu \mathrm{m} / \mathrm{s}$, (c) $20 \mu \mathrm{m} / \mathrm{s}$, (d) $100 \mu \mathrm{m} / \mathrm{s}$, and (e) $200 \mu \mathrm{m} / \mathrm{s}$.

pressure and shear activation energy values occurred at $2 \mu \mathrm{m} / \mathrm{s}$ for the mixture containing $30 \mathrm{vol} \%$ methyl oleate. In contrast, the lowest pressure activation energy occurred at $200 \mu \mathrm{m} / \mathrm{s}$ for the mixture containing $10 \mathrm{vol} \%$ methyl oleate. This could be correlated with the higher compressibility behavior of this mixture, as observed in Fig. 6, where a smaller increase in volume was expected, leading to a less desirable load-carrying capacity.

In an attempt to better correlate the effects of the methyl oleate composition on the activation energy terms at different sliding velocities for the tested ZDDP mixtures, the values determined in Figs. 10 and 11 were averaged across the applied normal loads for a given sliding velocity. Figure 12 illustrates the averaged pressure and shear activation energy values, which are mapped against the added methyl oleate compositions and sliding velocities. Through these contour maps, it is now possible to summarize that higher pressure and shear activation energies tend to occur around $40 \mu \mathrm{m} / \mathrm{s}$ for all levels of methyl oleate compositions added to ZDDP. Chong 

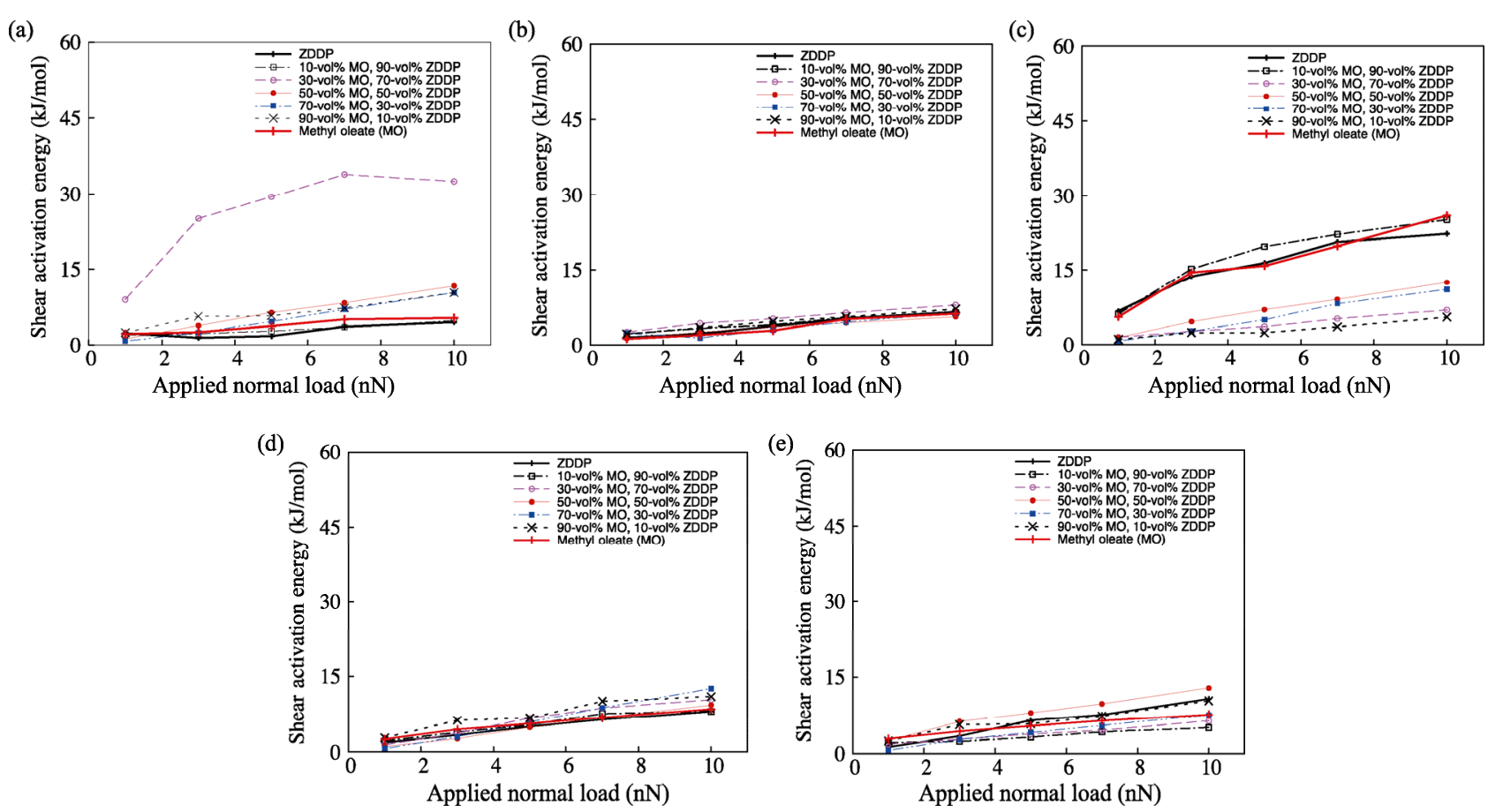

Fig. 11 Shear activation energy values for ZDDP with increasing amount of methyl oleate at different applied normal loads and AFM-probe sliding velocities: (a) $2 \mu \mathrm{m} / \mathrm{s}$, (b) $10 \mu \mathrm{m} / \mathrm{s}$, (c) $20 \mu \mathrm{m} / \mathrm{s}$, (d) $100 \mu \mathrm{m} / \mathrm{s}$, and (e) $200 \mu \mathrm{m} / \mathrm{s}$.
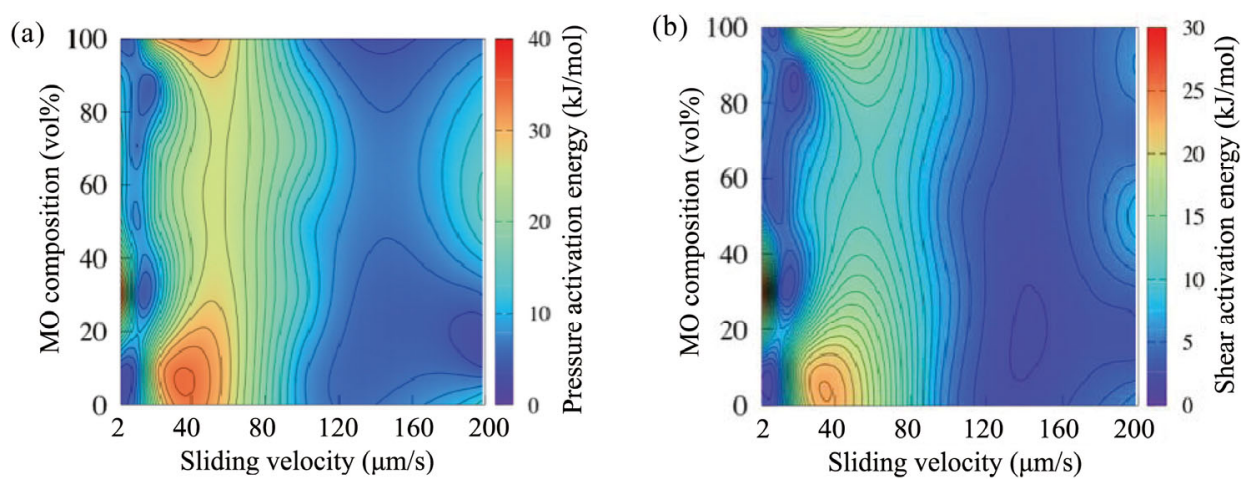

Fig. 12 Averaged pressure and shear activation energy values for ZDDP with increasing amount of methyl oleate molecules at different applied normal loads and AFM-probe sliding velocities: (a) averaged pressure activation energy, $P \Omega$; (b) Averaged shear activation energy, $\tau \phi$.

and $\mathrm{Ng}$ [38] relate the pressure activation energy term to the load-carrying capacity of the lubricant film. They suggested that an effective lubricant should have the highest possible pressure activation energy with the lowest possible shear activation energy. Following this assumption, considering the range of tested sliding velocities, an optimized tribological behavior could be surmised to occur for a compositions of ZDDP with 60 to $80 \mathrm{vol} \%$ of methyl oleate. Within this range of methyl oleate addition, the contact is expected to be less susceptible to a more drastic fluctuation of activation energy, especially around $40 \mu \mathrm{m} / \mathrm{s}$, and yet maintain sufficiently good shear and pressure activation energy properties.

Aside from the pressure and shear activation energies, another parameter introduced by the Eyring thermal activation energy approach is known as the activation energy to initiate sliding, $Q$. Figure 13 shows the change in this activation energy with respect to the sliding velocities at different mixtures 
of methyl oleate-ZDDP combinations. Generally, it is shown in Fig. 13(a) that the lowest activation energy to initiate sliding could be achieved for the ZDDP with 70 vol\% methyl oleate. This trend is observed when considering the coefficient of friction for the tested lubricants (see Fig. 8). When normalized against the activation energy values of neat ZDDP lubricants at the corresponding sliding velocities as mapped in Fig. 13(b), a reduction of as much as $28.9 \%$ in terms of activation energy to initiate sliding could be obtained under an optimized mixture of

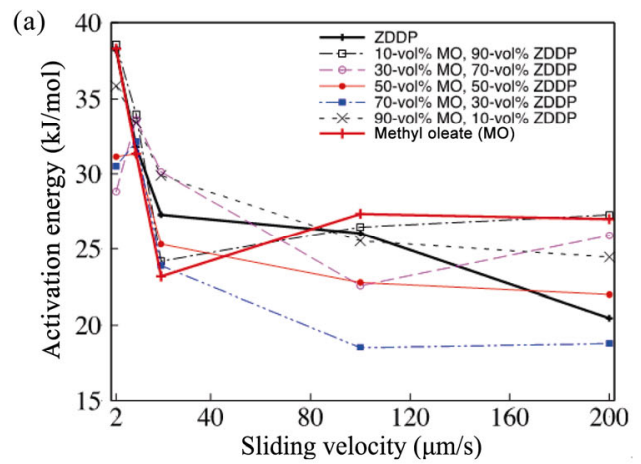

methyl oleate and ZDDP.

The Eyring thermal activation energy approach assumes that the motion of molecules is restricted by a potential barrier, $E$, which needs to be overcome in order to initiate sliding. The energy barrier can be determined using the pressure activation energy $(P \Omega)$ and shear activation energy $(\tau \phi)$ together with the activation energy to initiate sliding $(Q)$, as described in Eq. (1). The energy barrier $(E)$ for the tested methyl oleate-ZDDP mixtures is shown in Fig. 14 as a function of the applied normal load at

(b)

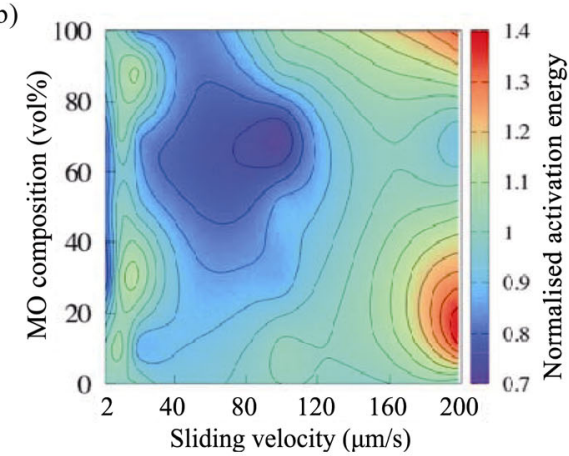

Fig. 13 Activation energy to initiate sliding, $Q$, for ZDDP with increasing amount of methyl oleate at varying AFM-probe sliding velocities: (a) activation energy; (b) normalized activation energy.

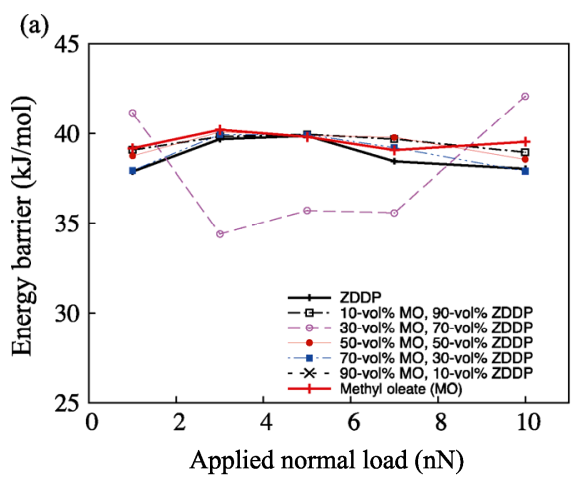

(b)

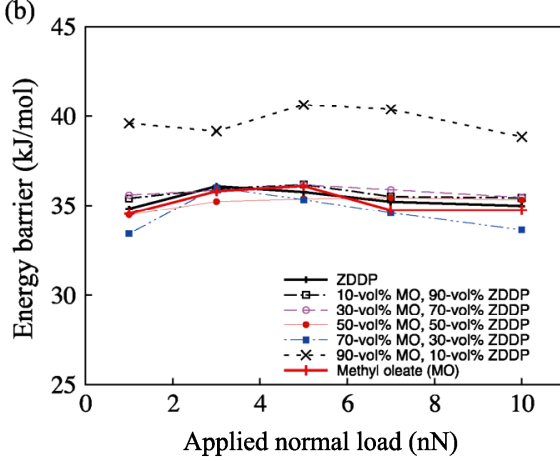

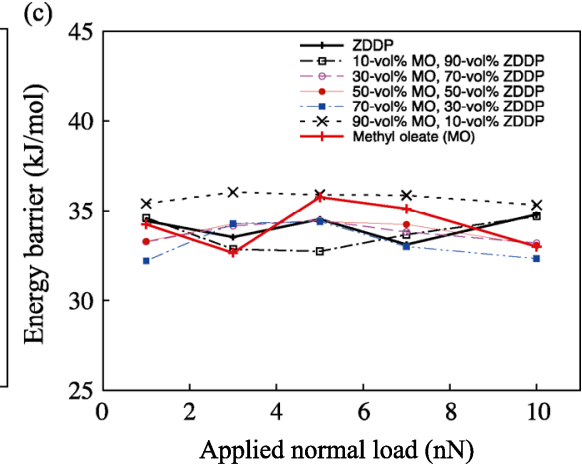
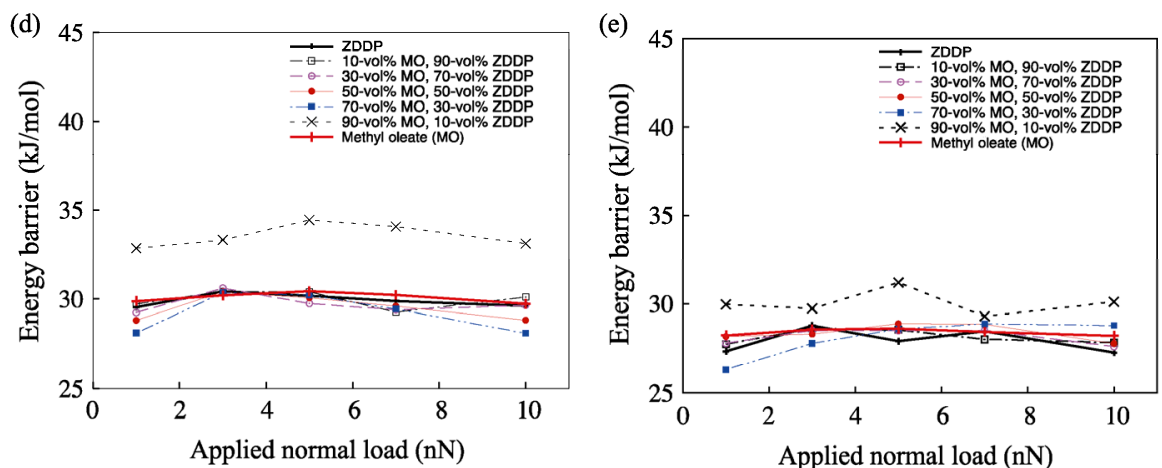

Fig. 14 Energy barrier, $E$, for ZDDP with increasing amount of methyl oleate molecules at different applied normal loads and AFM-probe sliding velocities: (a) $2 \mu \mathrm{m} / \mathrm{s}$, (b) $10 \mu \mathrm{m} / \mathrm{s}$, (c) $20 \mu \mathrm{m} / \mathrm{s}$, (d) $100 \mu \mathrm{m} / \mathrm{s}$, and (e) $200 \mu \mathrm{m} / \mathrm{s}$. 
different sliding velocities. For most of the tested conditions, the determined energy barrier values did not vary much with the applied normal load. In contrast, the highest energy barrier was observed for the methyl oleate-ZDDP mixture containing 10 vol\% methyl oleate for all tested sliding velocities, except for $2 \mu \mathrm{m} / \mathrm{s}$. By averaging this term against the applied normal load at the respective sliding velocity values, Fig. 15(a) shows that the smallest energy barrier could be achieved when ZDDP was added with $70 \mathrm{vol} \%$ methyl oleate. This is consistent with the results obtained for the activation energy required to initiate sliding, $Q$, in Fig. 13. By normalizing the values of neat ZDDP lubricants at the corresponding sliding velocities, it was shown that the potential energy barrier could be reduced by as much as $2.6 \%$ under the application of an optimized methyl oleate-ZDDP combination.

\section{Conclusions}

In biodiesel-fueled CI engines, the boundary lubrication properties of additives in fully formulated engine lubricants could be adversely affected by the presence of biodiesel. Therefore, the present study sought to determine the nano-tribological properties of ZDDP when diluted with methyl oleate at different volumetric proportions, through the use of an LFM coupled with a fluid imaging technique, which simulates a surface asperity-pair contact along a boundarylubricated rough surface conjunction. From the measured data, it is observed that ZDDP in the

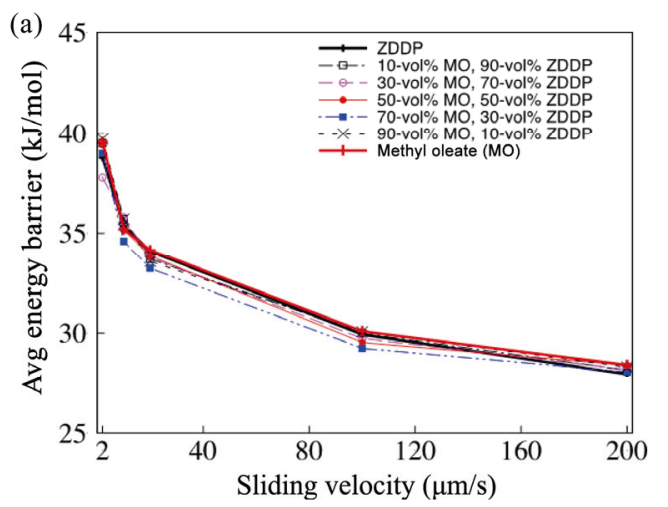

presence of up to $70 \mathrm{vol} \%$ of methyl oleate generated the lowest friction force and coefficient of friction (0.068-0.085) of all the tested conditions. Interestingly, these properties were also shown to be tribologically better than those of both neat ZDDP and neat methyl oleate, respectively.

The measured friction forces at different applied normal loads and sliding velocities were then interpreted using the Eyring thermal activation energy approach. The synergistic interaction observed between ZDDP and 70 vol\% methyl oleate was determined to be a result of the need to overcome an approximately $2.6 \%$ smaller potential energy barrier, E, when compared to neat ZDDP. The activation energy to initiate sliding, $Q$, was also calculated to be $28.9 \%$ less than that of neat ZDDP. At this concentration value, the fluid mixture also achieved the highest possible pressure activation energy (related to the load-carrying capacity of the boundary film) with the lowest possible shear activation energy (related to shearing of the boundary film). Thus, this demonstrates that an optimum proportion between additives (e.g., ZDDP) and fatty acid methyl ester (e.g., methyl oleate) does exist, which once determined, could potentially lead to synergistic nano-tribological effects along the boundary lubrication operating regime. Such findings could be useful when designing engine lubricants, especially in formulating the amount and proportion of additives required for lubricants used in biodiesel-fueled engines.

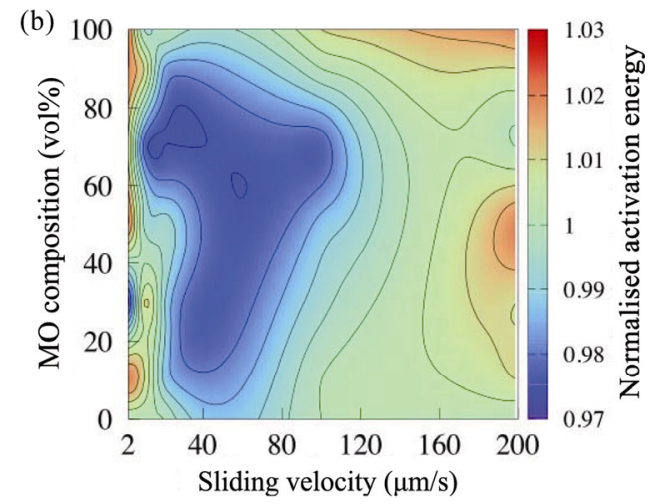

Fig. 15 Activation energy barrier, E, for ZDDP with increasing amount of methyl oleate at varying AFM-probe sliding velocities: (a) averaged energy barrier; (b) normalized activation energy barrier. 


\section{Acknowledgements}

The authors would like to acknowledge the support provided by the Ministry of Higher Education, Malaysia through the Fundamental Research Grant Scheme (FRGS) Phase 2018/1, awarded to Universiti Teknologi Malaysia (R.J130000.7851.5F055) and University of Southampton Malaysia (FRGS/1/2018/ TK10/USMC/02/1). The authors would also like to express their gratitude towards the experimental support given by the Centre for Biofuel and Biochemical Research (CBBR), Universiti Teknologi PETRONAS, Malaysia.

Open Access: This article is licensed under a Creative Commons Attribution 4.0 International License, which permits use, sharing, adaptation, distribution and reproduction in any medium or format, as long as you give appropriate credit to the original author(s) and the source, provide a link to the Creative Commons licence, and indicate if changes were made.

The images or other third party material in this article are included in the article's Creative Commons licence, unless indicated otherwise in a credit line to the material. If material is not included in the article's Creative Commons licence and your intended use is not permitted by statutory regulation or exceeds the permitted use, you will need to obtain permission directly from the copyright holder.

To view a copy of this licence, visit http://creativecommons.org/licenses/by/4.0/.

\section{References}

[1] IEA. https://www.iea.org/statistics, 2019.

[2] OICA. Vehicles in use. http://www.oica.net/category/ vehicles-in-use/, 2019.

[3] Graboski M S, McCormick R L. Combustion of fat and vegetable oil derived fuels in diesel engines. Prog Energy Combust Sci 24(2): 125-164 (1998)

[4] Murillo S, Míguez J L, Porteiro J, Granada E, Morán J C. Performance and exhaust emissions in the use of biodiesel in outboard diesel engines. Fuel 86(12-13): 1765-1771 (2007)

[5] Xue J L, Grift T E, Hansen A C. Effect of biodiesel on engine performances and emissions. Renew Sustain Energy Rev 15(2): 1098-1116 (2011)
[6] Datta A, Mandal B K. A comprehensive review of biodiesel as an alternative fuel for compression ignition engine. Renew Sustain Energy Rev 57: 799-821 (2016)

[7] Hajjari M, Tabatabaei M, Aghbashlo M, Ghanavati H. A review on the prospects of sustainable biodiesel production: A global scenario with an emphasis on waste-oil biodiesel utilization. Renew Sustain Energy Rev 72: 445-464 (2017)

[8] Abdelfattah M S H, Abu-Elyazeed O S M, El Mawla E A, Abdelazeem M A. On biodiesels from castor raw oil using catalytic pyrolysis. Energy 143: 950-960 (2018)

[9] Tenenbaum D J. Food vs. fuel: Diversion of crops could cause more hunger. Environ Health Perspect 116(6): A254-A257 (2008)

[10] Ansari N A, Sharma A, Singh Y. Performance and emission analysis of a diesel engine implementing polanga biodiesel and optimization using Taguchi method. Process Saf Environ Prot 120: 146-154 (2018)

[11] Rahman W U, Fatima A, Anwer A H, Athar M, Khan M Z, Khan N A, Halder G. Biodiesel synthesis from eucalyptus oil by utilizing waste egg shell derived calcium based metal oxide catalyst. Process Saf Environ Prot 122: 313-319 (2019)

[12] Lijó L, González-García S, Bacenetti J, Moreira M T. The environmental effect of substituting energy crops for food waste as feedstock for biogas production. Energy 137: 1130-1143 (2017)

[13] Lee J, Lee K, Sohn D, Kim Y M, Park K Y. Hydrothermal carbonization of lipid extracted algae for hydrochar production and feasibility of using hydrochar as a solid fuel. Energy 153: 913-920 (2018)

[14] Rajak U, Nashine P, Verma T N. Assessment of diesel engine performance using spirulina microalgae biodiesel. Energy 166: 1025-1036 (2019)

[15] Martin J M, Matta C, De Barros Bouchet M I, Forest C, Le Mogne T, Dubois T, Mazarin M. Mechanism of friction reduction of unsaturated fatty acids as additives in diesel fuels. Friction 1(3): 252-258 (2013)

[16] Geller D P, Goodrum J W. Effects of specific fatty acid methyl esters on diesel fuel lubricity. Fuel 83(17-18): 2351-2356 (2004)

[17] Knothe G, Steidley K R. Lubricity of components of biodiesel and petrodiesel. The origin of biodiesel lubricity. Energy Fuels 19(3): 1192-1200 (2005)

[18] Thornton M J, Alleman T L, Luecke J, McCormick R L. Impacts of biodiesel fuel blends oil dilution on light-duty diesel engine operation. SAE Int J Fuels Lubr 2(1): 781-788 (2009)

[19] Morcos M, Parsons G, Lauterwasser F, Boons M, Hartgers W. Detection Methods for Accurate Measurements of the Fame Biodiesel Content in Used Crankcase Engine Oil. SAE, 2009.

[20] Andreae M, Fang H, Bhandary K. Biodiesel and Fuel 
Dilution of Engine Oil. SAE, 2007.

[21] Kotrba R. Understanding the post-injection problem. Biod Mag 5(5) (2008)

[22] Fang H L, Alleman T L, McCormick R L. Quantification of Biodiesel Content in Fuels and Lubricants by FTIR and NMR Spectroscopy. SAE, 2006.

[23] Shanta S M, Molina G J, Soloiu V. Tribological effects of mineral-oil lubricant contamination with biofuels: A pin-on-disk tribometry and wear study. Adv Tribol 2011: 820795 (2011)

[24] Gulzar M, Masjuki H H, Varman M, Kalam M A, Zulkifli N W M, Mufti R A, Liaquat A M, Zahid R, Arslan A. Effects of biodiesel blends on lubricating oil degradation and piston assembly energy losses. Energy 111: 713-721 (2016)

[25] Arumugam S, Sriram G. Effect of bio-lubricant and biodiesel-contaminated lubricant on tribological behavior of cylinder liner-piston ring combination. Tribol Trans 55(4): 438-445 (2012)

[26] Singh Y, Singla A, Kumar A, Kumar D. Friction and wear characteristics of jatropha oil-based biodiesel blended lubricant at different loads. Energy Sources A 38(18): 2749-2755 (2016)

[27] Singh P, Goel V. Effect of bio-lubricant on wear characteristics of cylinder liner-piston ring and camtappet combination in simulated environment. Fuel 233: 677-684 (2018)

[28] Wei L, Duan H T, Jia D, Jin Y L, Chen S, Liu L, Liu J F, Sun X M, Li J. Motor oil condition evaluation based on on-board diagnostic system. Friction 8(1): 95-106 (2020)

[29] Hamdan S H, Chong W W F, Ng J H, Chong C T, Zhang H. Nano-tribological characterisation of palm oil-based trimethylolpropane ester for application as boundary lubricant. Tribol Int 127: 1-9 (2018)

[30] Tormos B, Ramírez L, Johansson J, Björling M, Larsson R. Fuel consumption and friction benefits of low viscosity engine oils for heavy duty applications. Tribol Int 110: 23-34 (2017)

[31] Habibullah M, Masjuki H H, Kalam M A, Zulkifli N W M, Masum B M, Arslan A, Gulzar M. Friction and wear characteristics of Calophyllum inophyllum biodiesel. Ind Crops Prod 76: 188-197 (2015)

[32] Balakumar R, Sriram G, Arumugam S. Investigation of friction and wear characteristics of waste ayurvedic oil biodiesel blends. Adv Sci Eng Med 10(3-5): 472-475 (2018)
[33] Barsari M A N, Shirneshan A. An experimental study of friction and wear characteristics of sunflower and soybean oil methyl ester under the steady-state conditions by the four-ball wear testing machine. J Tribol 141(4): 044501 (2019)

[34] Ruggiero A, D’Amato R, Merola M, Valašek P, Müller M. Tribological characterization of vegetal lubricants: Comparative experimental investigation on jatropha curcas L. oil, rapeseed methyl ester oil, hydrotreated rapeseed oil. Tribol Int 109: 529-540 (2017)

[35] Xiao H P, Zou H Y, Liu S H, Li C M. An investigation of the friction and wear behavior of soybean biodiesel. Tribol Int 131: 377-385 (2019)

[36] Hamdan S H, Chong W W F, Ng J H, Ghazali M J, Wood R J K. Influence of fatty acid methyl ester composition on tribological properties of vegetable oils and duck fat derived biodiesel. Tribol Int 113: 76-82 (2017)

[37] Maru M M, Almeida C M, Silva R F, Achete C A. Assessment of boundary lubrication in biodiesels by nanotribological tests. Energy 55: 273-277 (2013)

[38] Chong W W F, Ng J H. An atomic-scale approach for biodiesel boundary lubricity characterisation. Int Biodeterior Biodegradation 113: 34-43 (2016)

[39] Hamdan S H, Chong W W F, Ng J H, Chong C T, Rajoo S. A study of the tribological impact of biodiesel dilution on engine lubricant properties. Process Saf Environ Prot 112: 288-297 (2017)

[40] Chong W W F, Rahnejat H. Nanoscale friction as a function of activation energies. Surf Topogr Metrol Prop 3(4): 044002 (2015)

[41] Li Q, Kim K S, Rydberg A. Lateral force calibration of an atomic force microscope with a diamagnetic levitation spring system. Rev Sci Instrum 77(6): 065105 (2006)

[42] Briscoe B J, Evans D C B. The shear properties of Langmuir-blodgett layers. Proc Roy Soc A 380(1779): 389-407 (1982)

[43] He M Y, Blum A S, Overney G, Overney R M. Effect of interfacial liquid structuring on the coherence length in nanolubrication. Phys Rev Lett 88(15): 154302 (2002)

[44] Umer J, Morris N, Rahmani R, Balakrishnan S, Rahnejat H. Nanoscale frictional characterisation of base and fully formulated lubricants based on activation energy components. Tribol Int 144: 106115 (2020)

[45] Jacobson B O. Rheology and Elastohydrodynamic Lubrication. Amsterdam (Netherlands): Elsevier, 1991. 


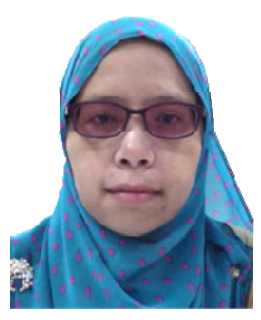

Siti Hartini HAMDAN. She received her bachelor in Licence Pro Production Industrielle in 2006 from IUT Aix en Provence, Universitaire Aix Marseille 2, France. She obtained her MEng degree from Universiti Kebangsaan Malaysia (UKM), Malaysia in 2011 before receiving

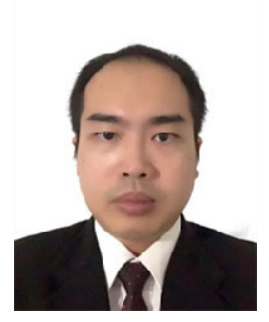

William Woei Fong CHONG. He received his BEng degree (Hons) in mechanical in 2007 from Universiti Teknologi Malaysia (UTM), Johor, Malaysia. Then, he obtained his M.S. degree in automotive product engineering and Ph.D. degree in engineering from Cranfield University, United her Ph.D. degree in engineering from University of Southampton, United Kingdom in 2015. She is currently a senior lecturer at University Kuala LumpurMalaysian Institute of Chemical \& Bioengineering Technology (UniKL-MICET), Melaka, Malaysia. Her research interests include lubrication science and biodiesel lubricity.

Kingdom in 2009 and 2012, respectively. He is currently a senior lecturer and also a research fellow at Automotive Development Centre (ADC) in the School of Mechanical Engineering, Faculty of Engineering, UTM. His research areas cover automotive tribology, biodegradable lubricants, and interfacial phenomena governed by boundary friction. 